\title{
EFFECT OF COUNT AND STITCH LENGTH ON SPIRALITY OF SINGLE JERSEY KNIT FABRIC
}

\author{
Md. Azharul Islam', Md. Faizul Haque ${ }^{2}$, Abu Naser Md. Ahsanul Haque ${ }^{3}$, Dewan Murshed Ahmed ${ }^{4}$ \\ ${ }^{1}$ Senior Lecturer, Daffodil International University, Shukrabad, Dhaka-1207, Bangladesh \\ ${ }^{2}$ Senior Lecturer, Daffodil International University, Shukrabad, Dhaka-1207, Bangladesh \\ ${ }^{3}$ Senior Lecturer, Daffodil International University, Shukrabad, Dhaka-1207, Bangladesh \\ ${ }^{4}$ Assistant Professor, National Institute of Textile Engineers and Researches, Savar, Dhaka, Bangladesh
}

\begin{abstract}
The following paper focuses on change in spirality due to stitch length and count variation.This work was carried out with 12 samples of single jersey knit fabrics which were scoured and bleached with $\mathrm{NaOH}$ and $\mathrm{H}_{2} \mathrm{O}_{2}(35 \%$ strength), dyed with reactive dye (Remazol Yellow RR reactive class) and were finished as standard procedure. After finishing the samples were tested for spirality and compared between different stitch length and count. The result obtained in this research indicated that spirality increases strongly due to increase of stitch length when count of yarn is fixed and on fixed stitch length spirality increases with the increment of count.
\end{abstract}

Keywords: Spirality, Count, Stitch length.

\section{INTRODUCTION}

Spirality is a common problem in weft and warp knitted fabric. Generally is the compactness of fabric which reduces the spirality tendency of it. Spirality appears mostly in single jersey knitted fabrics. In case of double jersey fabrics spirality level is found very much low. If samples are tested before compacting and after compacting, spirality will be greater in the previous one [1]. But fact is that, spirality can be reduced in different ways but cannot be removed from fabric.

Akter N. et al. [2] mentioned that spirality is described by the size of the angle made between the wales of a fabric and a line drawn perpendicular to the courses of that fabric. They have noted that spirality in a fabric is caused by the relaxation of torsion forces in the yarn and a fabric which is knitted with a highly twisted yarn will have higher spirality problem in result.

Count is a numerical value, which express the coarseness or fineness (diameter) of the yarn and also indicate the relationship between length and weight (the mass per unit length or the length per unit mass) of that yarn [3]. Therefore the concept of yarn count has been introduced which specifies a certain ratio of length to weight. $\mathrm{He}$ mentioned that fineness of the yarn is usually expressed in terms of count. Most of the knitted yarn is expressed by English cotton count system $(\mathrm{Ne})$.

The following formula is used to calculate count, $\mathrm{Ne}=$ $\left(L^{*} w\right) /\left(W^{*} l\right)$. Where, $N e=$ Yarn count or numbering system, $W=$ Weight of the sample at the official regain in the unit of the system, $L=$ Length of the sample, $l=$ Unit of length of the sample and $w=$ Unit of weight of the sample.
Celik O. et al. [4] in their article had proposed a method based on image-processing techniques, specifically the Fast Fourier Transform, for obtaining the directions of wale and course for measuring the angle of spirality. And they experimented with the method and said that the algorithm was quite satisfactory for determining the angle of spirality in knitted fabrics.

De Araujo M. D. et al. [5] studied the effect of spinning technology on the spirality of jersey fabrics for some $100 \%$ cotton and 50/50 cotton/polyester blend yarns. They found that the blend yarns produce less spirality than $100 \%$ cotton yarns. Moreover, they have mentioned that each spinning technology influences on the degree of spirality of knit fabrics.

According to Lord P. R. [6] the autoclaving of the yarns can be a solution of reducing twist liveliness as well as the associated difficulties in fabric manufacturing. This can improve different properties of the fabric and properly relaxed, open-end yarn produces a fabric with good appeal and reasonable shrinkage with acceptable strength and abrasion resistance. And twist less yarns result good handle, luster and zero spirality.

Islam A. M. et al [7] studied the spirality along with shrinkage and GSM to observe the suitable machine gauge. Better and acceptable spirality was found for 24 gauge machine with different counts and stitch length of fabric. 
Impress-Newtex Composite Textiles Ltd. Gorai, Mirzapur, Tangail.
FROM NOINCTL, - F. DYE - 06 REVISION NO: 00

\begin{tabular}{|c|c|c|c|c|c|c|c|c|c|c|c|c|c|}
\hline \multicolumn{14}{|c|}{ Recipe Sheet } \\
\hline \multicolumn{2}{|c|}{ Color: : } & Orange & \multicolumn{3}{|c|}{ Batch No. } & \multicolumn{2}{|c|}{6767} & \multicolumn{2}{|c|}{ Chemical Cost } & 2090.88 & \multicolumn{2}{|l|}{ Date } & \\
\hline \multicolumn{2}{|c|}{ Buyer : } & DGM Sir & \multicolumn{3}{|c|}{ Quantity (Kg) } & \multicolumn{2}{|c|}{55} & \multicolumn{2}{|c|}{ Dyes Cost } & 1784.08 & \multicolumn{2}{|c|}{ Rope Length : } & \\
\hline \multicolumn{2}{|c|}{ Order : } & Development & \multicolumn{3}{|c|}{ Yarn Lot } & \multicolumn{2}{|c|}{ Kamal-22/13 } & \multicolumn{2}{|c|}{ Total Cost } & 3874.96 & \multicolumn{2}{|c|}{ Reel Speed : } & \\
\hline \multicolumn{2}{|c|}{ Fabric : } & Average & \multicolumn{2}{|c|}{ Yarn Count } & : & \multicolumn{2}{|c|}{$30^{3 / 1}$} & \multicolumn{2}{|c|}{ Chemical Cost(Per Kg) } & 38.02 & \multicolumn{2}{|c|}{ Pump Speed : } & \\
\hline \multicolumn{2}{|c|}{ M/C-No: } & 06 & \multicolumn{2}{|c|}{ Finish Dia } & $:$ & \multicolumn{2}{|c|}{-} & Dyes Co & er $\mathrm{Kg}$ ) & 32.44 & Levellin & ng $P^{\prime \prime}:$ & \\
\hline & er(l.) & 605 & Finis: & h GSM & $:$ & & i & Average & $\underline{t(\operatorname{Per~Kg})}$ & 70.45 & Dyebati & h $\mathrm{P}^{\mathrm{H}}:$ & \\
\hline & $e x$ & 2.2300 & Lique & r Ratio( $\mathrm{N}$ & 1:L) : & 1 & 11 & Dyeing & & Reactive & Cycle Ti & ime: : & \\
\hline $\begin{array}{l}\text { S1. } \\
\text { No }\end{array}$ & & Dyes \& Chemicals & & $\begin{array}{l}\% \text { (wt } \\
\text { of fab.) }\end{array}$ & $\mathrm{Gm} / \mathrm{L}$. & & Kg usec & & Additio: & $\begin{array}{l}\text { Quantity } \\
\text { g) }\end{array}$ & \begin{tabular}{c|} 
Unit \\
Price
\end{tabular} & $\begin{array}{l}\text { Total } \\
\text { Price } \\
\end{array}$ & $\begin{array}{c}\text { Cost } \\
\text { (Per Kis: }\end{array}$ \\
\hline & Acot: & Adod Solution & $\nabla$ & & & & Pret & treatm & & & & & \\
\hline & Mat. & erge CRC & $\checkmark$ & & 0.30 & $00 \mathrm{k}$ & 2. $1818:$ & $500 \mathrm{~m}$ & & & 680 & 123.42 & \\
\hline & Ma-s & abte & $\checkmark$ & & 0.30 & $00 \mathrm{k}$ & $181 \mathrm{~g}$ & $500 \mathrm{~m}$. & & & 675 & 122.51 & \\
\hline & - Jinser & ECO CBA & - & & 1.50 & $00 \mathrm{k}$ & $907_{B}$ & $500 \mathrm{~m}$ & & $100^{\circ} \mathrm{C} \times 40^{\prime} \mathrm{R}$ & 115 & 104.36 & \\
\hline & Caust & K. Soda & 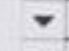 & & 1.50 & $00 \mathrm{k}$ & .9078 & $500 \mathrm{~m}$. & & & 68.5 & 62.16 & \\
\hline & Hydre & gen Peraxide(50\%) & 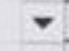 & & 2.00 & $01 \mathrm{k}$ & 2108 & $000 \mathrm{~m}$. & & & 34 & 41.14 & \\
\hline-7 & & & 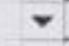 & & & & & & & Normal Hot & 0 & 0.00 & \\
\hline 4 & & & $\nabla$ & & & & & & & $80^{\circ} \mathrm{C} \times 10^{\prime} \mathrm{R}$ & 0 & 0.00 & \\
\hline & Acetic & Aod & $\boldsymbol{v}$ & & 0.60 & $00 \mathrm{k}$ & $363 \mathrm{~g}$ & $000 \mathrm{~m}$. & & & 116 & 42.11 & \\
\hline & Jutex & Ryne OEM & $\boldsymbol{v}$ & & 0.50 & $00 \mathrm{k}$ & $302 \mathrm{~g}$ & $500 \mathrm{~m}$. & & $P^{\prime \prime}=4.5-5.0$ & 150 & 45.38 & \\
\hline & - & & 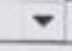 & & & & & & & & 0 & 0.00 & 9.84 \\
\hline & & & & & & & React & tive Dy & & & & & \\
\hline 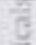 & Masc & our EXC & $\checkmark$ & & 0.30 & $00 \mathrm{~kg}$ & $181 \mathrm{~g}$ & $500 \mathrm{~m}$. & & & 953 & 172.97 & \\
\hline 2 & Jindev & 0.225 & $\boldsymbol{v}$ & & 0.50 & $00 \mathrm{~kg}$ & 3028 & $500 \mathrm{~m}$. & & $P^{\prime \prime}=6-6.5$ & 135 & 40.84 & \\
\hline ¿ & & & 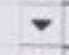 & & & & & & & & 0 & 0.00 & 3.89 \\
\hline & Rema & col. Orange RR & 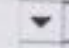 & 2.2000 & $01 \mathrm{~kg}$. & $210 \mathrm{~g}$ & $00 \mathrm{~m}$ & & & & 1461 & 1767.81 & \\
\hline & Rema. & rol.Red RR & 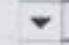 & 0.0300 & $00 \mathrm{~kg} \cdot \mathrm{C}$ & $016 \mathrm{~g}:$ & $00 \mathrm{~m}$. & & & & 986 & 16.27 & \\
\hline & & & $\boldsymbol{\nu}$ & & & & & & & & 0 & 0.00 & 32.44 \\
\hline E & Glauk: & er Sult & $\boldsymbol{v}$ & & 60.00 & $36 \mathrm{~kg}$ & $300 \mathrm{~g}$ & $000 \mathrm{~m}$ & & & 16.8 & 609.84 & \\
\hline$\frac{1}{2}$ & Soda: & Whi light & 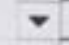 & & 16.00 & $09 \mathrm{~kg}$ & $680 \mathrm{~B}$ & $000 \mathrm{~m}$. & & $p^{\prime \prime}=10.7-11.3$ & 37.15 & 359.61 & \\
\hline 등 & & & $>$ & & & & & & & & 0 & 0.00 & 17.63 \\
\hline & & & & & & & After & treatn & & & & & \\
\hline & Accetic & Aod & 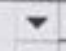 & & 0.80 & $00 \mathrm{~kg}$ & $484 \mathrm{~g} . \mathrm{C}$ & $000 \mathrm{~m}$. & & Hot & 116 & 56.14 & \\
\hline 3 & Maso & ap NC & $r$ & & 0.30 & $00 \mathrm{kp}$ & $181 \mathrm{~g} \cdot 5$ & $500 \mathrm{~m}$ & & $90^{\circ} \mathrm{C} \times 20^{\prime} \mathrm{R}$ & 777 & 141.03 & \\
\hline & Acetic & Acid & $\checkmark$ & & 0.60 & $00 \mathrm{~kg}$ & $363 \mathrm{~g}$ & $000 \mathrm{~m}$. & & & 116 & 42.11 & \\
\hline है & Ecotix & & 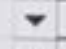 & & 1.00 & $00 \mathrm{~kg}$ & $60 S_{B}$ & $000 \mathrm{~m}$. & & $P^{\prime \prime}=4-5$ & 210 & 127.05 & \\
\hline & Cepre & on UN.P. & $\checkmark$ & & 1.50 & $00 \mathrm{~kg}$ & $907 \mathrm{~B}:$ & $500 \mathrm{~m}$ & & $35^{\circ} \mathrm{CX} 10^{\prime} \mathrm{D} \& 10^{\prime} \mathrm{R}$ & 232 & 0.21 & 6.66 \\
\hline
\end{tabular}

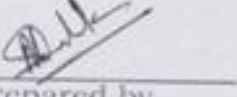

Prepared by

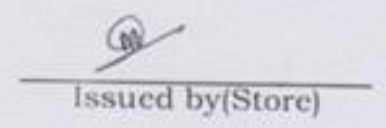

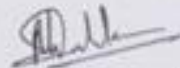

Shift in-charge(Dyeing

Fig 1: Dyeing recipe 


\section{MATERIALS \& METHODS}

\subsection{Fabric Production Unit}

Total 12 (twelve) samples were knitted differently having 3 $\mathrm{kg}$ for each by keeping same machine settings. A 22 inch diameter and 24 gauge circular knitting machine (Orizio, Italy) was selected for producing these samples. After knitting, all the samples were conveyed to dyeing section for wet treatments.

\subsection{Wet Processing Unit}

A sample dyeing machine (Fong's, Taiwan) was selected for dyeing all the samples at a time. A suitable recipe was selected. All the samples were dyed and sent to finishing section for drying and compacting. A fixed setting was chosen for drying (Santex, Switzerland) and compacting (Santex, Switzerland) in open form. The dyeing recipe that was used is given in figure 1. Compaction confirms the quality and specific dimensions of samples. After finishing samples were sent for spirality test.

\subsection{Spirality Tests for Knitted Fabrics}

Spirality of the tested sample is appeared after washing. As a result one of the side seams comes at front of the sample. Spirality percentage depends on fabric torque and garment structure. Two pieces of $50 \mathrm{~cm} \times 50 \mathrm{~cm}$ fabric was taken for test. Conditioning was done by putting the sample in the table for 4 hours before starting test. The benchmark was given as $35 \mathrm{~cm} \times 35 \mathrm{~cm}$. Then the sample was stitched in three sides by over lock sewing machine and one side remained unstitched. After that the sample was washed in washing machine (LG, China) and dried on tumble dryer. The calculation was done in the following method.

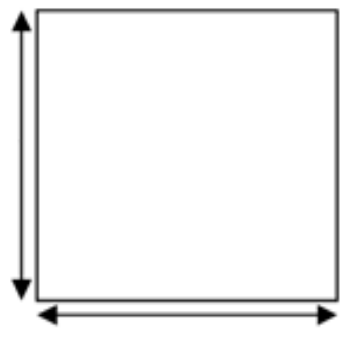

S

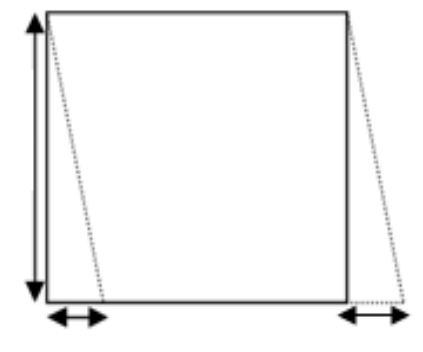

$\mathrm{S}_{1}$
$\mathrm{S}_{2}$
Fig 2: Spirality calculation

In figure 2, if total length, $S=X \mathrm{~cm}$, twist in one end $S_{1}=Y$ $\mathrm{cm}$, twist in another end $\mathrm{S}_{2}=\mathrm{Z} \mathrm{cm}$, average spirality $=$ $(\mathrm{Y}+\mathrm{Z}) / 2=\mathrm{M} \mathrm{cm}$, then- Spirality $=\mathrm{M} / \mathrm{X}^{*} 100$.

Table 1: Spirality in stitch variation

\begin{tabular}{|l|l|l|l|}
\hline Fabric type & Count $(\mathrm{Ne})$ & $\begin{array}{l}\text { Stitch length } \\
(\mathrm{mm})\end{array}$ & Spirality\% \\
\hline \multirow{2}{*}{$\begin{array}{l}\text { Single } \\
\text { Jersey } \\
\text { (Plain) }\end{array}$} & 34 & 2.6 & 0.9 \\
\cline { 2 - 4 } & 34 & 2.65 & 1 \\
\cline { 2 - 4 } & 34 & 2.7 & 1.5 \\
\cline { 2 - 4 } & 34 & 2.75 & 2 \\
\hline
\end{tabular}

\begin{tabular}{|l|l|l|l|} 
& 34 & 2.8 & 2.1 \\
\cline { 2 - 4 } & 34 & 2.9 & 3.1 \\
\cline { 2 - 4 } & 34 & 2.95 & 4.2 \\
\hline
\end{tabular}

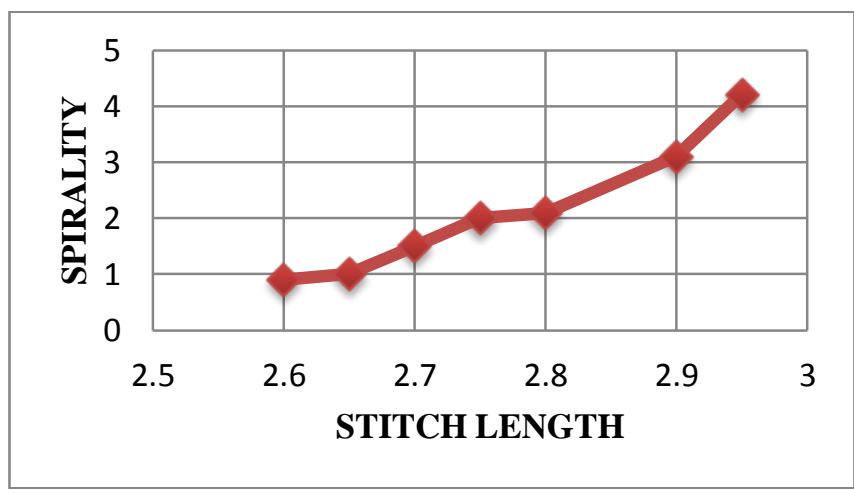

Graph 1: Graphical representation of spirality in stitch length variation

Table 2: Spirality in count variation

\begin{tabular}{|l|l|l|l|}
\hline Fabric type & Count $(\mathrm{Ne})$ & $\begin{array}{l}\text { Stitch length } \\
(\mathrm{mm})\end{array}$ & Spirality\% \\
\hline \multirow{4}{*}{$\begin{array}{l}\text { Single } \\
\text { Jersey } \\
\text { (Plain) }\end{array}$} & 40 & 2.6 & 4.7 \\
\cline { 2 - 4 } & 34 & 2.6 & 4 \\
\cline { 2 - 4 } & 30 & 2.6 & 3.50 \\
\cline { 2 - 4 } & 28 & 2.6 & 2.7 \\
\cline { 2 - 4 } & 26 & 2.6 & 2 \\
\hline
\end{tabular}

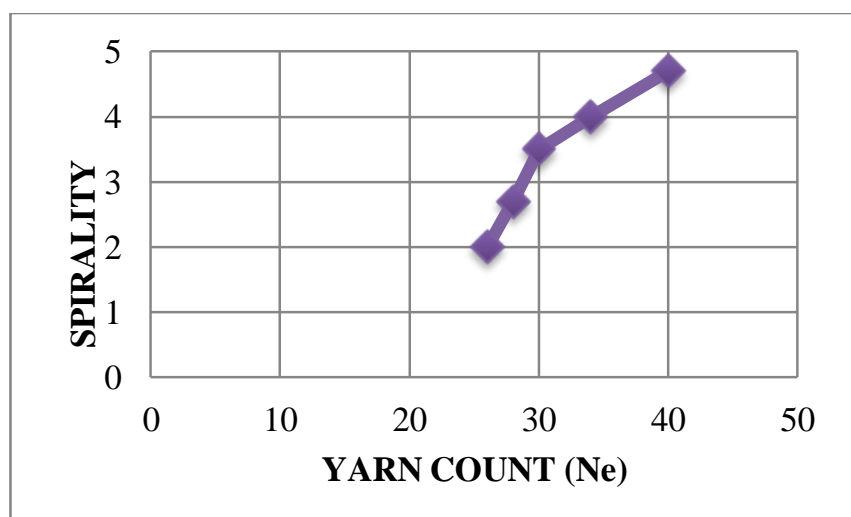

Graph 2: Graphical representation of spirality in count variation

\section{RESULTS \& DISCUSSION}

\subsection{Spirality in Stitch Variation}

It can be seen in table 1 and graph 1 that spirality is increased due to increase of stitch length. This was due to the fact that higher stitch length has more chance to twisting tendency for their loop height than loop height of lower stitch length.

\subsection{Spirality in Count Variation}

Table 2 and graph 2 shows that spirality also increased due to increase of yarn count. This was due to the fact that higher count means more no of loop density per inch present in the fabric so more number of loops has changed to twist than coarser yarn in the fabric. 
Higher count means long staple fibre is present in the yarn but more free space will found in the fabric than lower yarn count (when stitch length is fixed). It focused that the compactness of lower count fabric will be higher than that of higher count fabric. As the higher count fabric has low compactness than lower count fabric. That's why higher count fabric has more twisting tendency than lower count fabric.

\section{CONCLUSIONS}

Finally this paper reveals the relation among yarn count, stitch length and spirality. Following decisions can be made from this experimental work-

1. Spirality of knitted fabric increases with stitch length. Because higher stitch length gets more chance of twisting.

2. Spirality also increases with higher count or in higher density of loops for fixed stitch length and machine gauge.

To manufacture a fabric which has less spirality problem, it is suggested to always maintain a keep an eye on the stitch length of fabric and count of the yarn. Using lower count of yarn as well as a lower stitch length according as far as possible can be a good solution for the fabric manufacturers to get rid of the headache of spirality problem.

\section{ACKNOWLEDGEMENTS}

The authors gratefully acknowledge the help \& support from Mr. Shankar Dayal Biswas, Deputy General Manager and Mr. Sumon Chandra Das, Deputy Manager, Impress-Newtex Composite Textile Ltd, Gorai, Mirzapur, Tangail, Bangladesh.

\section{REFERENCES}

[1]. M. A. Shahid, F. Ahmed, A. K. M. Mahabubuzzaman, M. A. Hannan, A. N. Khan, Spirality in cotton knit fabrics before and after compacting using selected yarn count and stitch length, 2010, Journal of Innovation and Development Strategy, Vol. 4(2), pp. 11-17.

[2]. Nasrin Akter, Nahida Akter, Effects of combed and carded yarn on weft knitted finished fabric quality, 2011, International Journal of Engineering \& Technology (IJETIJENS), Vol. 11(6), pp. 113-119.

[3]. Thomas Woodhouse, Yarn Counts and Calculations, 1921, Oxford Technical Manual, pp. 1-17.

[4]. Ozkan Celik, Nuray Ucar, Seniz Ertugrul, Determination of spirality in knitted fabrics by image analysis, 2005, Fibres and Textiles in Eastern Europe, Vol. 13 No. 3(51), pp 47-49.

[5]. De Araujo M. D., Smith G. W., Spirality of knitted fabrics, part II: the effect of yarn spinning technology on spirality, 1989, Textile Research Journal, Vol. 59 (6), pp. 350-356.

[6]. Lord P. R., Mohamed M. H., Ajgaonkar D. B., The performance of open-end, twistless, and ring yarns in weft knitted fabrics, 1974, Textile Research Journal, Vol. 44(6), pp. 405-414.

[7]. Md. Azharul Islam, Abu Naser Md. Ahsanul Haque, Selection of suitable machine gauge by considering the GSM, shrinkage and spirality of single jersey knit fabric. 3, January 2014, Research Journal of Science \& IT management, Vol. 3, pp. 50-55.

\section{BIOGRAPHIES}

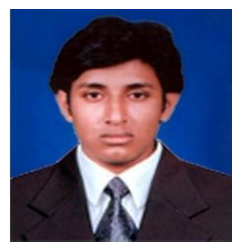

Md. Azharul Islam had completed his M.Sc from Mawlana Bhashani Science and Technology University and B.Sc from College of Textile Technology, University of Dhaka. He has more than five years of teaching experience.
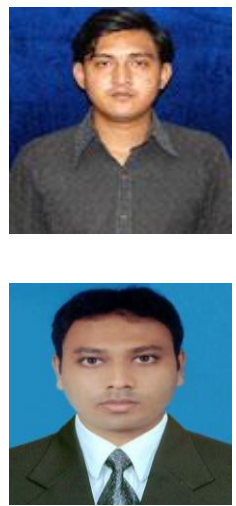

experience.

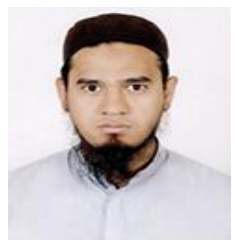

Md. Faizul Haque had completed B.Sc from College of Textile Technology, University of Dhaka and M.Sc from Daffodil International University. He had 4 years of industrial experience and more than 4 years of teaching experience.

Abu Naser Md. Ahsanul Haque had completed his M.Sc from Mawlana Bhashani Science and Technology University and B.Sc from College of Textile Technology, University of Dhaka. He has more than five years of teaching

Dewan Murshed Ahmed Had completed B.Sc from College of Textile Technology, University of Dhaka and continuing M.Sc from Bangladesh University of Textiles (BUTEX). He has 5 years' experience in teaching area. 